\title{
COMBINED MITRAL AND AORTIC STENOSIS
}

\author{
BY \\ ANDREW G. MORROW, WILLIAM C. AWE, AND EUGENE BRAUNWALD
}

From the Clinic of Surgery and Cardiology Branch, National Heart Institute, Bethesda, Maryland, U.S.A.

Received April 16, 1962

Rheumatic fever commonly affects both the mitral and aortic valves, and in a significant proportion of patients with rheumatic heart disease the physical findings of both mitral and aortic $\vec{c}$ stenosis are present. Detailed evaluation, however, will usually reveal that only one of the lesions is of hæmodynamic importance and responsible for the patient's disability. Less commonly, left heart catheterization will reveal pressure gradients across both valves of sufficient magnitude to indicate that a combined operative approach will be necessary.

At the National Heart Institute we have recently studied eight patients with combined mitral and aortic stenosis. In each, mitral commissurotomy and aortic valvotomy were carried out by a closed technique. The clinical findings in these patients, the operative method employed, and the results of their pre- and post-operative hæmodynamic evaluations form the basis of this report.

\section{Clinical and Hamodynamic Findings}

The ages of the eight patients ranged from 20 to 48 years, and six of them were women. A clear history of rheumatic fever was given by six patients. Exertional dyspnœa had been experienced by all of them, and the majority complained also of orthopnœa and paroxysmal nocturnal dyspnœa of varying severity. In two patients hæmoptysis, and in two others arterial embolism, had occurred. It is of interest that only one patient (V.J.) described anginal pain and none had experienced vertigo or syncope.

On examination, the typical auscultatory and phonocardiographic findings of aortic stenosis and mitral stenosis were evident in every patient. A rough systolic ejection murmur, usually accompanied by a thrill, was audible at the base of the heart and radiated along the carotid vessels. In seven a soft blowing diastolic murmur along the left sternal border was audible as well. In each patient a rumbling diastolic murmur was present at the apex and an opening snap was heard in seven. An apical systolic murmur was present in four. Although the auscultatory findings suggested that aortic and/or mitral regurgitation was present in some of them, in none of them was a regurgitant lesion considered, on clinical grounds, to be of significant magnitude. A representative phonocardiogram recorded in patient F.S. is reproduced in Fig. 1.

Radiographs revealed that the heart of every patient was generally enlarged and prominence of the left atrium was evident in each. In three an enlarged left ventricle was present and in two (H.J. and F.L.) intracardiac calcification was thought to be present at fluoroscopic study. The radiographical appearance of the heart of patient F.S. is shown in Fig. 2. With the exception of V.J., each patient had a normal sinus rhythm, and in five of these left atrial enlargement was evident, as indicated by a tall $P$ wave in lead II of more than 0.12 sec. duration. The electrical axis was normal in six patients and deviated to the left in two. No ventricular predominance was evident in six while the pattern of left ventricular hypertrophy was recorded in the other two, one of whom also exhibited left axis deviation. 


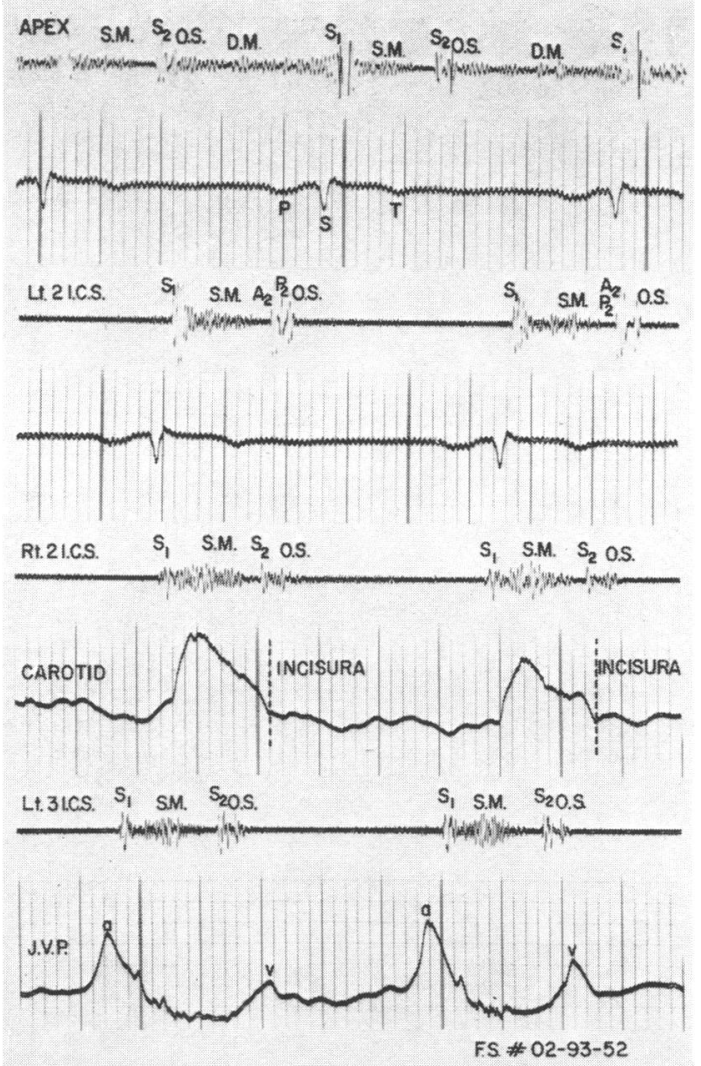

FIG. 1.-Phonocardiogram of patient F.S. S1 and S2 indicate the first and second heart sounds, O.S. the opening snap, S.M. the systolic murmur, and D.M. the diastolic murmur. The tracings were recorded from above at the apex, left 2 nd intercostal space, right 2 nd intercostal space, and left 3rd intercostal space. J.V.P. is the jugular venous pulse. A diamond-shaped ejection murmur is present in the aortic area. There is narrow splitting of the second heart sound and an opening snap of the mitral valve is seen, following aortic closure by only $0.06 \mathrm{sec}$. At the apex a low pitched holodiastolic murmur follows the opening snap and there is presystolic accentuation. A prominent " $a$ " wave is evident in the jugular venous pulse.

The results of the pre-operative right and left heart catheterizations are summarized in Table I. Left heart catheterization was carried out by the trans-septal (Brockenbrough, Braunwald, and Ross, 1962) or the trans-bronchial route (Morrow, Hallar, and Sharp, 1957) and systemic arterial pressure was measured in the brachial artery. All pressures were recorded on a multichannel photographic oscillograph. Mean gradients were established by planimetry, and in the determination of the aortic valve gradient an appropriate correction was made for the time delay between the central aortic and brachial arterial pressure pulses. The cardiac index was determined by the indicator dilution method and the areas of the stenotic orifices estimated from the formulæ of Gorlin and Gorlin (1951).

The right ventricular or pulmonary arterial systolic pressures were moderately raised (32 to $52 \mathrm{~mm} . \mathrm{Hg}$ ) in each of the six patients in whom right heart catheterization was performed.

The left atrial mean pressure was raised and a filling gradient across the mitral valve was present in every patient. In four of the seven in whom it was measured the cardiac index at rest was abnormally low $\left(<2.601 . / \mathrm{min} . / \mathrm{m}^{2}{ }^{2}\right)$. The effective orifice of the mitral valve could be calculated in seven, and in each it was reduced below normal, the average orifice area being $1.4 \mathrm{~cm} .^{2}$ In every patient a systolic difference between the left ventricular and brachial arterial pressures 


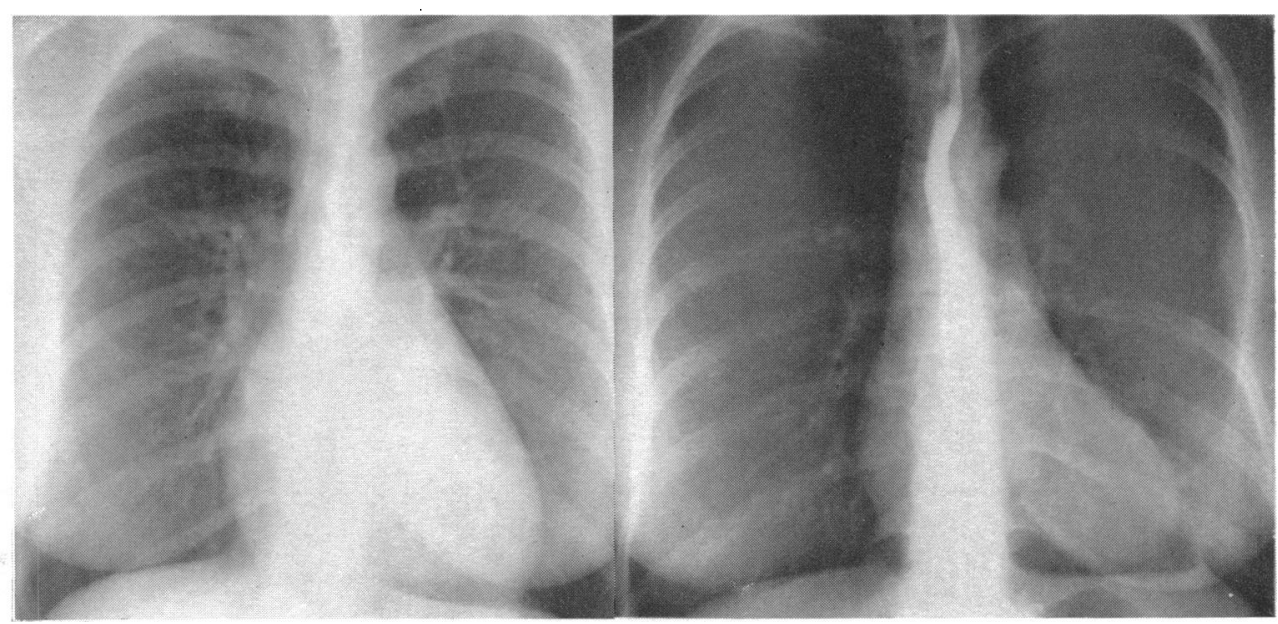

A

B

FIG. 2.-Chest radiographs of patient F.S. Pre-operatively (A) the configuration of the heart is typical of isolated mitral stenosis with prominence of the left atrium and straightening of the left heart border. These changes are not apparent in the post-operative film (B).

TABLE I

Pre- and Post-Operative Hamodynamic Data in Patients with Combined Mitral and Aortic Stenosis

\begin{tabular}{|c|c|c|c|c|c|c|c|c|c|c|c|c|c|}
\hline \multirow{3}{*}{$\begin{array}{l}\text { Patient, } \\
\text { age, sex }\end{array}$} & \multirow[t]{3}{*}{ Status } & \multirow{3}{*}{$\underset{\text { (mth.) }}{\text { Interval }}$} & \multicolumn{8}{|c|}{ Pressures (mm. Hg) } & \multirow{3}{*}{$\begin{array}{c}\text { Cardiac } \\
\text { index } \\
(1 . / \mathrm{min} . / \\
\left.\mathrm{m} .{ }^{2}\right)\end{array}$} & \multicolumn{2}{|c|}{$\begin{array}{l}\text { Orifice area } \\
\left(\mathrm{cm} .^{2}\right)\end{array}$} \\
\hline & & & \multirow{2}{*}{$\begin{array}{c}\text { Pul. } \\
\text { art. } \\
\text { or } \\
\text { rt. } \\
\text { vent.* }\end{array}$} & \multirow[t]{2}{*}{$\begin{array}{c}\text { Left } \\
\text { atrium } \\
\text { (mean) }\end{array}$} & \multicolumn{3}{|c|}{$\begin{array}{l}\text { Mitral diastolic } \\
\text { gradient }\end{array}$} & \multicolumn{2}{|c|}{$\begin{array}{l}\text { Aortic } \\
\text { systolic } \\
\text { gradient }\end{array}$} & \multirow[t]{2}{*}{$\begin{array}{c}\text { Brachial } \\
\text { artery }\end{array}$} & & \multirow[t]{2}{*}{ Mitral } & \multirow[t]{2}{*}{ Aortic } \\
\hline & & & & & $\begin{array}{l}0 \cdot 1 \\
\text { sec. }\end{array}$ & $\begin{array}{l}\text { End- } \\
\text { dia- } \\
\text { stolic }\end{array}$ & Mean & Peak & Mean & & & & \\
\hline $\begin{array}{l}\text { H.J. } \\
43 \text { M } \\
\text { E.M. } \\
27 \text { F } \\
\text { H.H. } \\
47 \text { F } \\
\text { F.L. } \\
40 \text { F } \\
\text { F.S. } \\
33 \text { F } \\
\text { V.J. } \\
\text { 48 F } \\
\text { R.P. } \\
\text { 20 M } \\
\text { I.T. } \\
\text { 38 F }\end{array}$ & $\begin{array}{l}\text { Pre-op } \\
\text { Post-op } \\
\text { Pre-op } \\
\text { Post-op } \\
\text { Pre-op } \\
\text { Post-op } \\
\text { Pre-op } \\
\text { Post-op } \\
\text { Pre-op } \\
\text { Post-op. } \\
\text { Pre-op } \\
\text { Post-op } \\
\text { Pre-op } \\
\text { Post-op } \\
\text { Pre-op } \\
\text { Post-op }\end{array}$ & $\begin{array}{c}8 \\
9 \\
8 \\
12 \\
12 \\
10 \\
7 \\
\begin{array}{c}\text { At } \\
\text { opera- } \\
\text { tion }\end{array}\end{array}$ & $\begin{array}{l}38 / 5^{*} \\
25 / 0^{*} \\
32 / 6^{*} \\
45 / 25 \\
34 / 14 \\
44 / 18 \\
48 / 6 \\
45 / 20 \\
24 / 2^{*} \\
32 / 12 \\
52 / 20 \\
33 / 7^{*} \\
-\end{array}$ & $\begin{array}{r}18 \\
8 \\
25 \\
9 \\
21 \\
16 \\
15 \\
18 \\
15 \\
7 \\
26 \\
20 \\
30 \\
12 \\
28 \\
20\end{array}$ & $\begin{array}{r}7 \\
2 \\
15 \\
3 \\
9 \\
5 \\
9 \\
7 \\
18 \\
4 \\
25 \\
18 \\
28 \\
7 \\
22 \\
8\end{array}$ & $\begin{array}{r}9 \\
0 \\
2 \\
0 \\
3 \\
0 \\
13 \\
2 \\
19 \\
0 \\
12 \\
5 \\
20 \\
0 \\
18 \\
0\end{array}$ & $\begin{array}{r}7 \\
2 \\
12 \\
3 \\
7 \\
4 \\
9 \\
6 \\
17 \\
3 \\
17 \\
8 \\
21 \\
5 \\
23 \\
4\end{array}$ & $\begin{array}{r}52 \\
0 \\
45 \\
20 \\
60 \\
88 \\
35 \\
12 \\
40 \\
15 \\
61 \\
34 \\
48 \\
0 \\
20 \\
0\end{array}$ & $\begin{array}{r}1 \\
0 \\
29 \\
19 \\
41 \\
58 \\
23 \\
13 \\
38 \\
10 \\
53 \\
33 \\
36 \\
0 \\
20 \\
0\end{array}$ & $\begin{array}{c}132 / 60 \\
140 / 65 \\
95 / 50 \\
120 / 55 \\
120 / 60 \\
96 / 60 \\
125 / 70 \\
140 / 70 \\
110 / 70 \\
104 / 58 \\
110 / 60 \\
200 / 105 \\
96 / 66 \\
145 / 50 \\
110 / 65 \\
120 / 70\end{array}$ & $\begin{array}{c}2 \cdot 72 \\
3 \cdot 51 \\
1 \cdot 91 \\
2 \cdot 67 \\
2 \cdot 56 \\
2 \cdot 34 \\
2 \cdot 30 \\
2 \cdot 96 \\
2 \cdot 50 \\
2 \cdot 40 \\
- \\
4 \cdot 10 \\
3 \cdot 46 \\
3 \cdot 10 \\
2 \cdot 26\end{array}$ & $\begin{array}{l}2 \cdot 5 \\
6 \cdot 9 \\
0 \cdot 71 \\
4 \cdot 9 \\
2 \cdot 1 \\
2 \cdot 7 \\
1 \cdot 5 \\
2 \cdot 6 \\
0 \cdot 6 \\
3 \cdot 4 \\
- \\
1.7 \\
2 \cdot 9 \\
1.0 \\
1.9\end{array}$ & $\begin{array}{l}0.74 \\
-0.68 \\
1.20 \\
0.70 \\
0.50 \\
0.90 \\
1.58 \\
0.43 \\
1.30 \\
- \\
1.35 \\
1.03 \\
-\end{array}$ \\
\hline
\end{tabular}


ndicated aortic stenosis. The effective orifice of the aortic valve was also calculated in seven ind averaged $0.83 \mathrm{~cm} .{ }^{2}$ The left atrial, left ventricular, and brachial arterial pressure pulses ecorded in patient E.M. are illustrative of the presence of both mitral and aortic stenosis (Fig. 3).

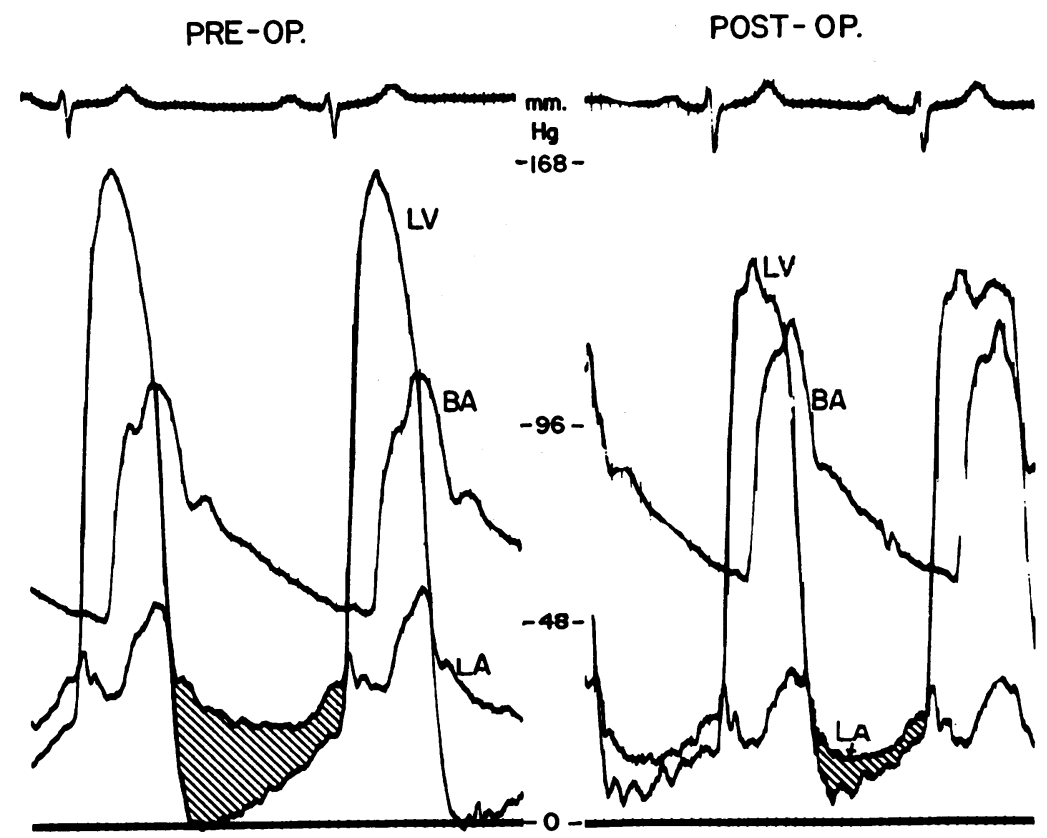

FIG. 3.-Intraoperative records of simultaneous left atrial (LA), left ventricular (LV), and brachial arterial (BA) pressures in patient E.M. The mitral diastolic gradient is indicated by the cross-hatched area. The reduction in the gradients across both valves following dilatation is evident.

\section{Operative Technique and Findings}

Closed transventricular dilatation was used in each patient for the relief of both mitral and aortic stenosis. A left postero-lateral incision is made and the chest is entered through the bed of the resected sixth rib. The pericardium is incised, anterior to the phrenic nerve, from the apex of the heart to its base. After the pressures in the left atrium, left ventricle, and brachial artery have been recorded and the cardiac output measured, a mattress suture of heavy silk is placed in the apex of the left ventricle and digital exploration of the mitral valve carried out through the atrial appendage. After assessment of the anatomical and pathological findings, and partial digital commissurotomy, a two-bladed Tubbs dilator is passed from the left ventricle. This is then completed by controlled dilatation, usually accomplished in stages by appropriate adjustment of the dilator blades.

The left atriotomy is closed with a clamp and the Tubbs dilator replaced with a Glover aortic valve dilator. This is guided into the aortic valve by external palpation of the aortic root and opened to its full extent $(4 \mathrm{~cm}$.). Dilatation in two planes is performed and the instrument is then withdrawn. Bleeding from the ventriculotomy is controlled by a tourniquet on the mattress suture and the pressure measurements and cardiac output determinations are repeated. Additional dilatation of either valve may then be carried out if satisfactory reductions in the valve gradients are not apparent on the monitoring oscilloscopic screen. The incisions in the atrium and ventricle are then closed. 
In all patients the mitral valve, by palpation, was found to be severely stenotic, but in only one $\stackrel{c}{.}$ (V.J.) was there calcification. Mitral regurgitation was also present in patients H.J. and L.T., but $\overrightarrow{\vec{s}} \underset{+}{\vec{*}}$ the magnitude of regurgitant flow, as judged by palpation, was considered to be trivial. No patient $\vec{\sigma}$ had an atrial thrombus. Little information could be obtained concerning the anatomical nature of $\frac{}{\overline{0}}$ the aortic valve lesion in any of the patients. In none, however, was calcification evident by pal- $\frac{\bar{\sigma}}{\vec{D}}$ pation of the aortic root or when the dilator was engaged in the valve.

In every patient the appearance of the heart at operation was characteristic of mitral stenosis, i.e. the right ventricle, pulmonary artery, and left atrium were prominent, and the left ventricle was never $\vec{\circ}$ found to be significantly enlarged.

\section{RESULTS OF OPERATION}

There were no major post-operative complications. Two patients developed atrial fibrillation in the immediate post-operative period but in each a normal sinus mechanism was restored after the ir administration of quinidine. All the patients are living and all have experienced striking sympto- 8 matic improvement during follow-up intervals of one to three years. Each has returned to normal or near normal activity, and both of the men are gainfully employed as clerk and truck driver, respectively. Seven of the eight have returned for post-operative cardiac catheterization, and the $\vec{c}$ data obtained at post-operative study are included in Table $I$. A significant fall in the right $\frac{\mathbb{D}}{8}$ ventricular or pulmonary arterial pressure was noted in four of the five patients in whom comparative studies were carried out. In six of the eight, striking reductions in the mean left atrial pressure and the mean diastolic mitral valve gradient were observed, and in these six the end-diastolic mitral gradient was abolished. In patients F.L. and V.J. post-operative enddiastolic gradients of 2 and $5 \mathrm{~mm}$. $\mathrm{Hg}$ respectively indicated mild residual mitral stenosis. The ? average increase in the calculated mitral orifice area was over 150 per cent in the seven patients in whom it was measured pre- and post-operatively. The aortic systolic gradient was abolished in three and reduced to a hæmodynamically acceptable level in four others. In patient H.H. there was residual aortic stenosis of moderate severity. In no patient was there clinical or hæmodynamic evidence that mitral or aortic regurgitation resulted from dilatation of the valves, and in those in whom a mild regurgitant lesion of either valve was present before operation it was not aggravated by the procedure.

The average values for the major hæmodynamic indices in all patients, before and after operation, are presented in Table II.

TABLE II

Average Hamodynamic Indices of Eight Patients Before and After Operation

\begin{tabular}{|c|c|c|c|c|}
\hline & & & Pre-operative & Post-operative \\
\hline $\begin{array}{l}\text { Left atrial mean pressure (m } \\
\text { Mitral mean diastolic gradie } \\
\text { Peak aortic systolic gradient } \\
\text { Mean aortic systolic gradien } \\
\text { Aortic valve area (cm.2) } \\
\text { Mitral valve area (cm.2) } \\
\text { Cardiac index }\left(1 . / \mathrm{min} . / \mathrm{m}^{2}\right)\end{array}$ & $\begin{array}{l}\text { m. Hg) } \\
\text { ht }(\mathrm{mm} . \dot{\mathrm{Hg}}) \\
(\mathrm{mm} . \mathbf{H g}) \\
\begin{array}{lc}(\mathrm{mm} . & \mathrm{Hg}) \\
\ldots & \ldots \\
\ldots & \ldots \\
\ldots & \ldots\end{array}\end{array}$ & $\begin{array}{l}\cdots \\
\cdots \\
\cdots \\
\cdots \\
\cdots \\
\cdots\end{array}$ & $\begin{array}{l}22 \\
14 \\
45 \\
35 \\
0 \cdot 83 \\
1 \cdot 4 \\
2 \cdot 74\end{array}$ & $\begin{array}{c}14 \\
4 \\
21 \\
17 \\
\text { Not calc.* } \\
3 \cdot 6 \\
2 \cdot 80\end{array}$ \\
\hline
\end{tabular}

*The average post-operative aortic valve area cannot be calculated since three patients had no residual aortic gradient.

\section{Discussion}

When surgically significant stenosis of both the mitral and aortic valves is present, the patient's history and symptoms will usually be those of mitral stenosis rather than aortic stenosis (Katznelson et al., 1960; Honey, 1961). The combined lesions are found far more often in women than in men, 
and a clear history of antecedent rheumatic fever is usually obtained (Uricchio et al., 1959; Likoff et al., 1955). Six of the eight patients described above are women and six of them had had rheumatic fever in childhood. Dyspnœea, orthopnœa, and fatiguability, the symptoms of mitral stenosis, were described almost universally. Only one patient of the present group had experienced anginal pain and none of them had had syncope. On examination, however, the presence of both lesions was readily apparent from the physical findings, and the characteristic murmurs of mitral stenosis and aortic stenosis were present in every patient.

When the results of clinical examinations indicate the presence of both mitral and aortic stenosis, precise hæmodynamic definition of the lesions by left heart catheterization is indicated. In such studies, carried out usually by the trans-septal route, the pressure gradient across each valve must be measured and determinations of the cardiac output must be made. Measurements of both pressure and flow are imperative because the proximal limitation of flow imposed by obstruction at the mitral valve may reduce the left ventricular output to such an extent that only a small aortic systolic gradient will be evident even though the aortic valve orifice is much restricted. These considerations are illustrated by the pre-operative hæmodynamic findings in patient E.M. (Table I). In this woman mitral stenosis was severe, the effective mitral orifice being only $0.71 \mathrm{~cm} .{ }^{2}$ A mean aortic systolic gradient of only $29 \mathrm{~mm}$. $\mathrm{Hg}$ was recorded, but when the abnormally low cardiac index, $1.91 . / \mathrm{min} . / \mathrm{m} .^{2}$, was taken into consideration and the effective aortic orifice size calculated, it was found to be critically reduced to $0.68 \mathrm{~cm} .{ }^{2}$ Had the cardiac output not been measured during the studies in this patient, the small aortic gradient might not have been considered an indication for aortic valvotomy. It is likely that in her the sudden relief of only the mitral lesion would have placed an intolerable burden on the unprepared left ventricle. This disastrous sequence of events was described in three patients reported by Uricchio and Likoff (1957).

Since 1958, patients with isolated mitral stenosis have been treated in this clinic by transventricular mitral commissurotomy, and the advantages of this method over other closed techniques seem well documented (Morrow and Braunwald, 1961). Open operations for mitral stenosis are reserved for patients with proved or suspected atrial thrombosis, combined mitral stenosis and regurgitation, or calcific mitral stenosis that has been found at exploration not to be amenable to dilatation. In isolated aortic stenosis, on the other hand, an open operation with debridement or valve replacement is always employed.

When the results of left heart catheterization indicate that both valves must be opened, the choice of the operative method must be made on all the circumstances of the individual case. Although the results of open operations on the mitral and aortic valves, with either debridement or partial or total replacement, have been gratifying, combined transventricular dilatation can be expected to provide safe and effective treatment in properly selected patients. The present experience indicates that the closed operation is applicable when the patient's symptoms are those of mitral stenosis; when left heart catheterization confirms the presence of severe mitral obstruction and a low cardiac output; when there is little or no radiological or electrocardiographic evidence of left ventricular hypertrophy, and when calcification of the aortic valve cannot be demonstrated. Open operation is clearly indicated when there is evidence of a regurgitant lesion of either valve of more than trivial magnitude, or when calcification of the aortic valve is clearly apparent on either radiographic or fluoroscopic study. On occasion, calcific aortic stenosis, accompanied by more or less severe aortic regurgitation, is found in conjunction with pure mitral stenosis. Under these circumstances closed transventricular dilatation of the mitral valve has been performed at the time of aortic valve replacement.

In the past, transventricular dilatation was occasionally employed in this clinic in patients with calcific aortic stenosis, but the operation was abandoned because of the high operative mortality and the poor hæmodynamic results that attended its use. It must be emphasized, therefore, that the anatomical alterations responsible for these poor results were, to a large extent, absent in the patients in this series. Presumably because of the accompanying mitral stenosis none of them had the hypertrophic, friable, and irritable left ventricle commonly seen in pure aortic stenosis. In addition, calcification of the aortic valve was never extensive enough to be evident at operation. These 
protective effects of mitral stenosis on the left ventricle and the stenotic aortic valve have become well recognized (Bailey et al., 1956) and apparently account for the safety and efficacy of the closed operation in the presence of the combined lesions. In addition, it appears likely that the presence of mitral stenosis in these patients leads to cardiac disability at an earlier stage of their illness than had aortic stenosis been present alone: As a result, patients with combined mitral and aortic stenosis are probably referred for operation before extensive calcification of the aortic valves has occurred.

\section{SUMMARY}

Eight patients are described in whom combined mitral and aortic stenosis was present. Although the presence of both lesions was evident by auscultation, the patients' symptoms and the radiographic and electrocardiographic findings were primarily those of mitral stenosis. Left heart catheterization in every patient revealed that both stenotic lesions were hæmodynamically significant, each was treated by closed transventricular dilatation of both the mitral and aortic valves. All patients are living and have experienced striking symptomatic improvement which has been reflected in the results of post-operative hæmodynamic evaluations. The importance of left heart catheterization in the pre-operative assessment of patients with evidence of the combined lesions and the factors that influence the choice of the operative method employed in their treatment are discussed.

\section{REFERENCES}

Bailey, C. P., Bolton, H. E., Nichols, H. T., Jamison, W. L. and Litwak, R. S. (1956). J. thorac. Surg., $31,375$. Brockenbrough, E. C., Braunwald, E., and Ross, J., Jr. (1962). Circulation, 25, 15.

Gorlin, R., and Gorlin, S. G. (1951). Amer. Heart J., 41, 1.

Honey, M. (1961). Brit. Heart J., 23, 545.

Katznelson, G., Jreissaty, R. M., Levinson, G. E., Stein, S. W., and Abelmann, W. H. (1960). Amer. J. Med., 29, 242.

Likoff, W., Berkowitz, D., Denton, C., and Goldberg, H. (1955). Amer. Heart J., 49, 394.

Morrow, A. G., and Braunwald, N. S. (1961). J. thorac. cardiovasc. Surg., 41, 225.

- Braunwald, E., Haller, J. A., Jr., and Sharp, E. H. (1957). Circulation, 16, 1033.

Uricchio, J. F., Goldberg, H., Sinah, K. P., and Likoff, W. (1959). Amer. J. Cardiol., 4, 479.

——, and Likoff, W. (1957). New Engl. J. Med., 256, 199. 